\title{
Mapping environmental susceptibility to Saint Louis encephalitis virus, based on a decision tree model of remotely- sensed data
}

\author{
Camilo H. Rotela ${ }^{1}$, Lorena I. Spinsanti ${ }^{2}$, Mario A. Lamfri ${ }^{1}$, Marta S. Contigiani ${ }^{2}$, Walter R. \\ Almirón ${ }^{3}$, Carlos M. Scavuzzo ${ }^{1}$ \\ ${ }^{1}$ Instituto de Altos Estudios Espaciales Mario Gulich, Comisión Nacional de Actividades Espaciales, Centro \\ Espacial Teófilo Tabanera, Córdoba, Argentina; ${ }^{2}$ Instituto de Virología Dr. J.M. Vanella, Facultad de Ciencias \\ Médicas, Universidad Nacional de Córdoba, Córdoba, Argentina; ${ }^{3}$ Centro de Investigaciones Entomológicas de \\ Córdoba, Facultad de Ciencias Exactas Físicas y Naturales Universidad Nacional de Córdoba, Córdoba, \\ Argentina
}

\begin{abstract}
In response to the first human outbreak (January - May 2005) of Saint Louis encephalitis (SLE) virus in Córdoba province, Argentina, we developed an environmental SLE virus risk map for the capital, i.e. Córdoba city. The aim was to provide a map capable of detecting macro-environmental factors associated with the spatial distribution of SLE cases, based on remotely sensed data and a geographical information system. Vegetation, soil brightness, humidity status, distances to water-bodies and areas covered by vegetation were assessed based on pre-outbreak images provided by the Landsat $5 \mathrm{TM}$ satellite. A strong inverse relationship between the number of humans infected by SLEV and distance to high-vigor vegetation was noted. A statistical non-hierarchic decision tree model was constructed, based on environmental variables representing the areas surrounding patient residences. From this point of view, $18 \%$ of the city could be classified as being at high risk for SLEV infection, while $34 \%$ carried a low risk, or none at all. Taking the whole 2005 epidemic into account, $80 \%$ of the cases came from areas classified by the model as medium-high or high risk. Almost $46 \%$ of the cases were registered in high-risk areas, while there were no cases $(0 \%)$ in areas affirmed as risk free.
\end{abstract}

Keywords: landscape epidemiology, remote sensing, risk map, Saint Louis encephalitis, Argentina.

\section{Introduction}

Saint Louis encephalitis (SLE) is a human, mosquito-borne viral disease, caused by the SLE virus (SLEV), a member of the Flaviviridae family. It is maintained in enzootic cycles primarily involving passerine birds and Culex mosquitoes (Monath, 1980). Widely distributed in the American continent, SLEV has been isolated from southern Canada to Argentina and is responsible for a great number of human infections in the United States. Humans are considered "dead-end" hosts and less than $1 \%$ of SLEV infections are clinically apparent ((Tsai et al.,1987, 1989). Severity ranges from a simple febrile headache to full-blown meningoencephalitis and increases with age, with encephalitis

\footnotetext{
Corresponding author:

Camilo Hugo Rotela

Instituto de Altos Estudios Espaciales Mario Gulich

Comisión Nacional de Actividades Espaciales

Centro Espacial Teófilo Tabanera

Ruta C 45 km 8, Falda del Cañete

5187 Córdoba, Argentina

Tel.+54 3547 431-000; Fax +54 3547 424-566

E-mail: crotela@conae.gov.ar
}

more frequently seen in people older than 60 years (Calisher and Poland, 1980; Calisher, 1994). According to serological evidence, SLE is widely distributed in Argentina reaching 50\% of the population in some locations (Sabattini, 1998; Spinsanti, 2000). Sporadic symptomatic cases of SLE have been reported since 1964 and SLEV strains have been isolated from humans, Culex mosquitoes and wild rodents (Sabattini et al., 1998). Between 1998 and 2000, the human SLEV seroprevalence in Córdoba City was estimated at $13.9 \%$ (Spinsanti et al., 2002) with the first clinical case detected in the summer of 2002 (Spinsanti et al., 2003). Later studies based on individuals who attended two different health centres in Córdoba City showed similar seroprevalence. The risk of infection was shown to be associated with the presence of garbage dumps in residential areas or with outdoor activities at dusk (Spinsanti et al., 2007). The first notified SLE outbreak in Argentina occurred in Córdoba province in late January 2005 and affected 47 persons, nine of whom died (Spinsanti et al., 2008). Two SLEV strains of genotype III were isolated from Culex quinquefasciatus and C. (Culex) interfor. Diaz 
et al. (2006a) and Spinsanti (2009) found increased human seroprevalence in samples emanating from public health centres of Córdoba City. In addition, studies performed in the city between 2001 and 2004 detected SLEV infection in other mosquito species, such as Aedes aegypti, Anopheles albitarsis, Cx. apicinus, Ae. (Ochlerotatus) albifasciatus, Ae. (Ochlerotatus) scapularis, and Psorophora spp. (Díaz, 2009).

When remote sensing became available, studies on vector-borne diseases focused on identifying and mapping vector habitats (Barnes and Cibula, 1979; Hayes et al., 1985), and assessed environmental factors related to vector biology (Rogers and Randolph, 1993; Kitron, 1998; Porcasi et al., 2006a,b). This enlarged the scope of epidemiology (Linthicum et al., 1999; Murray 2003; Rotela et al., 2007) and encouraged Wood et al. (1992) and Glass et al. (1992) to investigate the application of remote sensing and spatial analysis to identify and map landscape elements that collectively define vector and human population dynamics related to disease transmission. Indeed, landscape pattern analysis combined with spatial statistics, allows the recognition of risk predictors suitable for application in larger regions where field data are unavailable (Dister et al., 1997; Beck et al., 2000; Tran et al., 2004). Thus, an analysis based on remote sensing and geographical information systems (GIS) becomes a powerful tool for disease surveillance and intervention (Morrison et al., 1998; Rogers and
Randolph, 2003). In this context, spatial risk models for human exposure to vector-borne pathogens can be successfully constructed with epidemiological data (Eisen and Eisen, 2008). The main objective of this study was to establish the environmental risk levels of SLEV infection in Córdoba city based on the distribution of symptomatic cases and the macro-environmental characteristics provided by remote sensing and GIS.

\section{Material and methods}

\section{Study site}

SLE cases were detected predominantly in Córdoba City (located around latitude $31^{\circ} 24^{\prime} 30^{\prime \prime} \mathrm{S}$ and longitude $\left.64^{\circ} 11^{\prime} 02^{\prime \prime} \mathrm{W}\right)$, at $450 \mathrm{~m}$ above mean sea level (ASML) located in Córdoba province in central Argentina (Fig. 1). With a surface of $576 \mathrm{~km}^{2}$ and a population of approximately 1,5 million (Sbarato et al., 2004), the urban area constitutes around $37.2 \%$ of the city surface, which is surrounded by agricultural fields with vegetables, fruits, soya and wheat, interspersed with small native forest patches. The climate is a semi-dry temperate biome, with an important water deficit in winter, in spite of the relatively high annual precipitation level $(750$ and $800 \mathrm{~mm})$. The rainy season extends from October to March, with higher precipitation levels during December, January and February (Jarsún et al., 2003).

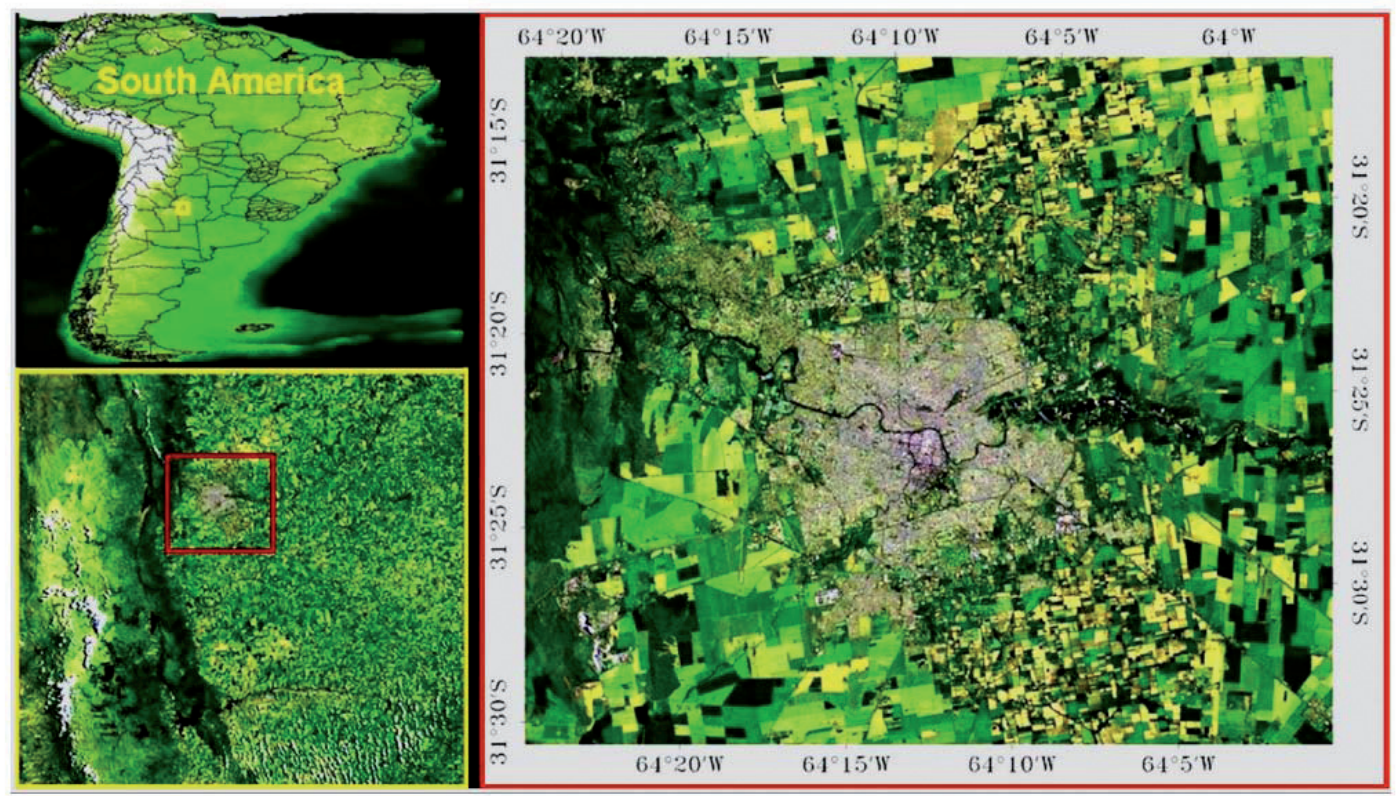

Fig. 1. South American digital elevation model based on shuttle radar topography mission (SRTM) and false colour NOAA AVHRR derived image (upper left). The complete Landsat 5 TM scene (RGB=B3-B2-B1) of the central area of Córdoba province is seen bottom left. The right section of the figure depicts a "zoom in" of the studied area (Landsat TM false colour image (RGB=B7-B5-B2), corresponding to the indicated red square area. 


\section{Study subjects}

The 2005 SLE outbreak started in late January, reaching the highest notification of cases during the second week of March and ending by May. Confirmed cases are defined by the presence of specific IgM antibody in cerebrospinal fluid (CSF) or serum plus $\geq 4$-fold increase or decrease in neutralizing SLEV antibody titres in the serum (mainly IgG) between paired samples (obtained at least 1 week apart), while a probable case is defined by the demonstration of SLEV-IgM antibody in serum or CSF (Spinsanti et al., 2008). Probable and confirmed SLEV cases were considered as positive cases in this study, resulting in 47 cases out of 72 patients studied in the whole province. Most patients had fever associated with meningeal signs, altered mental status, or both. The infection affected mainly people between 10 and 60 years of age $(52.2 \%)$ with $40.4 \%$ older than 60 years. The mean patient age was $47.8 \pm 24.6$ years (range: $7-87$ years). Males constituted $63.8 \%$ of those infected and $40 \%$ of all cases were either nonworking people or housewives.

\section{Geo-references}

A geo-referenced digital neighbourhood map of Córdoba City, provided by Córdoba municipality, allowed the location of 35 out of 39 SLE patient residences (four locations were not found), and the construction of daily human SLE incidence maps.

\section{SLE density map}

The average nearest neighbour analysis was performed using ArcMap 9.0 (ESRI, Redlands, CA, USA) to quantify the spatial distribution pattern of cases. We selected Euclidean distance and a -1.2 standard deviations Z-score. The value of observed mean distance/expected mean distance was 0.9 indicating that the somewhat dispersed pattern could be random. In spite of the lack of statistical significance, we used the Kernel density tool (ArcMap 9.0) to express the density of cases around each output raster cell of the case map (Silverman, 1986). Aiming at discrimination between high and low SLE density incidence areas with $99 \%$ statistical significance, we took the patient age variable into account and selected a search radius of 2,000 $\mathrm{m}$ (considering the Culex flight range and city surface) around each residence. To fit the Landsat 5 TM raster images scale, an output cell size of $30 \times 30$ $\mathrm{m}$ was chosen.

\section{Satellite imagery and preprocessing}

The Landsat-5 (L5) satellite was launched on 1 March 1984, with the Thematic Mapper (TM) earthimaging sensor onboard. The TM has six 30-m reflective bands and one 120-m thermal band. The TM bands have centre wavelengths of approximately 0.49 , $0.56,0.66,0.83,1.67,11.5$ and $2.24 \mathrm{~m}$, respectively, with raw and calibrated data products quantized to the 8-bit level (Chander et. al, 2007). The satellite orbit has a mean altitude of $705 \mathrm{~km}$ providing a 16-day temporal resolution, 233-orbit cycle over a $185-\mathrm{km}$ swath (http://landsat.usgs.gov/about_landsat5.php).

The Landsat 5 TM image (path: 229 - row: 82) was received by the CONAE ground station (Centro Espacial Teófilo Tabanera) on 4 January 2005, just before the first SLE notification. It was geo-referenced with the Envi 4.1 software, using image to image technique (Richards and Jia, 2006) and ground control points selected from Landsat 5TM base image (geo.tif format), obtained from "Earth science data interface at the global land cover facility" website (http:// glcfapp.umiacs.umd.edu:8080/esdi/index.jsp). With a 0.4 RSM error, a $1^{\text {st }}$ order polynomial warping function was performed, selecting nearest neighbour as the resampling method. TM digital numbers were converted to radiance (reflectance above the atmosphere) using Envi 4.1 software and available post-launch gains and offsets (http://landsat.usgs.gov/index.php).

\section{Generation of thematic maps}

An $882 \mathrm{~km}^{2}$ image subset, including Córdoba City and its immediate surroundings, was used to create a new set of environmental variables derived from the satellite image by means of Envi 4.1 (2004). These contained three tasseled cap indexes, i.e. soil brightness (represented as brightness), green vegetation (represented as greenness) and a third index estimating the interrelationship of soil and canopy moisture (the moisture status) (Kauth et al., 1979; Crist and Cicone, 1984; Jensen, 1986; Yang et al., 2006) and the normalized difference vegetation index (NDVI). The latter, derived from the red and near-infrared (NIR) Landsat TM and ETM bands, improved sensitivity of the forest structural and land cover categories. Responsive to changes in plant biomass, vigor and leaf-area (Jensen, 1986), negative NDVI values indicate absence of vegetation, while values near +1 correspond to dense, green vegetation. Positive values just above zero indicate vegetation with scarce covering such as rocks or exposed soil. 
Maps of landscape elements related to SLEV ecoepidemiology were elaborated by different techniques. The vegetation class map of Córdoba City and surroundings, containing parks, squares, wastelands, as well as vegetation along roads and railways or between crops (linear habitats) was prepared by selecting pixels with NDVI index threshold values between 0.62 and 1 . In order to eliminate the effect of building shadows on the radiometry of images, and to avoid erroneous classifications, we divided the row of satellite bands (B1-B2-B3-B5-B7) by the NIR band (band 4). Based on these corrected values, we generated qualitative hydrological maps that could be related to mosquito larval habitats. For this purpose, we applied a supervised maximum likelihood classification, creating three hydrological categories: lentic water bodies (ponds, lakes and quarries), lotic water bodies (La Cañada creek and the Suquía River) and a general hydrology map of the city (including lentic and lotic items). All these thematic maps were validated by the use of ground control points, expert field knowledge, and checked by high-resolution images from Google Earth (http://earth.google.com).

Distances or buffer zone images were created based on the thematic maps. In these images, every pixel had a value defined as the distance from that pixel to the nearest pixel of the selected class (or classes). A maximum distance value was designated and the result for any pixels with a distance larger than such a value was set to the maximum distance value. The following buffer images were created with a range from 0 to $5,700 \mathrm{~m}$ (0 to 200 pixels):

(i) distance to vegetation class (areas with high density and high vigor vegetation such as parks, squares, wastelands, green spaces and linear habitats), see Fig. 2;

(ii) distance to lentic water bodies (quarries, ponds, lakes, temporary ponds);

(iii) distance to lotic water bodies ("La Cañada” creek and "Suquía" river); and

(iv) distance to mixed water bodies (lotic and lentic together).

Finally, a synthetic image database was constructed containing all information from the new RS bands or layers created (Table 1 ).

\section{Statistical analysis and modeling}

By the use of the region of interest (ROI) tool (see Envi 4.1), each patient location was transformed from a single vector point (.evf format) into a ROI of $3 \times 3$ pixels, including their residencies (central pixel) and

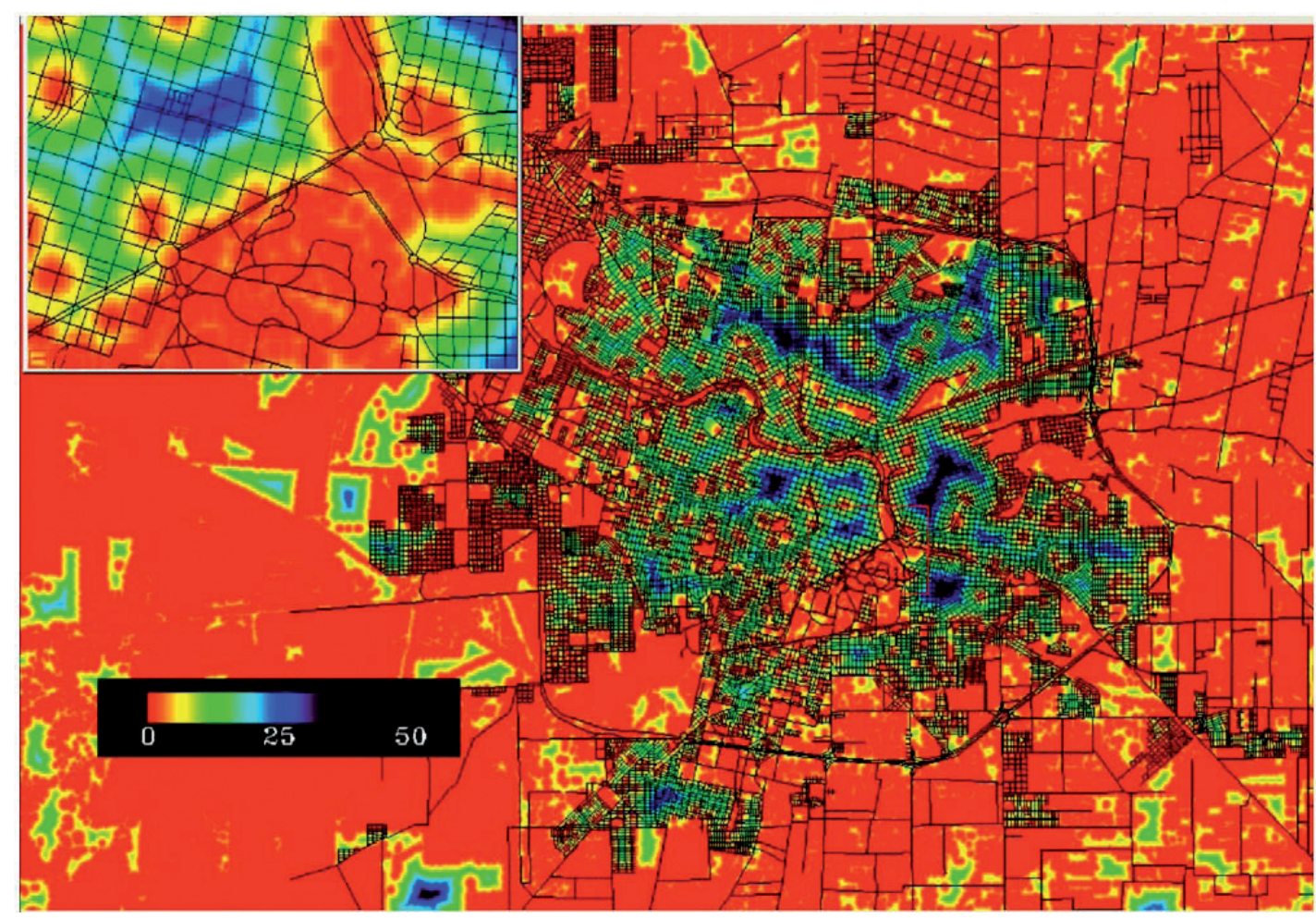

Fig. 2. Vegetation buffer zone image. Temperature colour ramp represents distances to the vegetation class expressed in pixel units ( $28.5 \times 28.5 \mathrm{~m}$ spatial resolution). Red pixels correspond to areas closer than $28.5 \mathrm{~m}$ from the high-vigor vegetation areas (derived from NDVI assessment). Black pixels correspond to areas farther away than approximately $850 \mathrm{~m}$. 
Table 1. Synthetic image structure showing all bands derived from Landsat 5 TM satellite sensor and GIS. Calibrated Landsat 5 TM bands 1, 2, 3, 5 and 7, were divided by band 4 (0.76$0.90 \mu \mathrm{m})$ to reduce the shadow effect of buildings and vegetation.

\begin{tabular}{ccc}
\hline Calibrated Landsat 5 TM bands & Wavelength $(\mu \mathrm{m})$ \\
\hline (1) & Band 1 & $0.45-0.52$ \\
(2) & Band 2 & $0.52-0.60$ \\
(3) & Band 3 & $0.63-0.69$ \\
(4) & Band 5 & $1.55-1.75$ \\
(5) & Band 7 & $2.08-2.35$ \\
\hline
\end{tabular}

Landsat 5 TM derived indexes:

(6) Normalized difference vegetation index (NDVI)

(7) Tassled Cap 1 - Brightness

(8) Tassled Cap 2 - Greenness

(9) Tassled Cap 3 - Third

\begin{tabular}{l}
\hline 200 pixels distance buffer image: \\
\hline (10) Distance to vegetation \\
(11) Distance to lentic water bodies \\
(12) Distance to lotic water bodies \\
(13) Distance to mixed water bodies \\
\hline
\end{tabular}

surrounding environment. This tool allows extracting information of a raster data set or a single band, by the ROI overlap area. The Córdoba region included 35 SLE patients $\left(258,859 \mathrm{~m}^{2}\right.$ or 315 pixels $)$, considered as samples of environmental SLEV risk areas, from where we obtained the statistical distribution of the 315 pixel values, for each of the 13 predictive variables derived from the Landsat image. Correlation between all variables was run, considering subsets obtained from each variable ROI of 315 pixels as input data. Redundant or highly correlated variables (Pearson's $\mathrm{P}=0.7$ to 1 ) were eliminated from the data base. From the remaining data, predictive variables were selected when discriminate function analysis, between ESL cases ROI and whole city pixels, were set at medium or high discrimination.

\section{The SLE environmental risk map}

A statistical, non-hierarchical decision tree model (Breiman et al., 1984; Venables \& Ripley, 1994) based on predictive variables was constructed taking into account parallelepiped classification approaches (Richards 1999; Albert et al., 2000). Envi 4.1 software was used to generate the decision tree model classification from TM imagery and its derived environmental information. In this non-hierarchical tree structure, each decision node results in two branches, and each expression within the decisiontree classifier, represents a single, binary decision (true or false for each pixel). At each new split in the tree, the same exercise is conducted and the tree grows until it reaches its terminal nodes, i.e. the leaves. This is known as the top-down approach (Xu et al., 2005) where each leaf represents a unique set of pixels, which defines the risk level output depending on the number of fulfilled decision nodes.

\section{Results}

The dispersal of notified SLE cases throughout the city during the disease outbreak is represented in Fig. 3. The principal part of the dispersion was observed between days 11 and 49 of the epidemic, with patients remaining in the central and north-central areas from

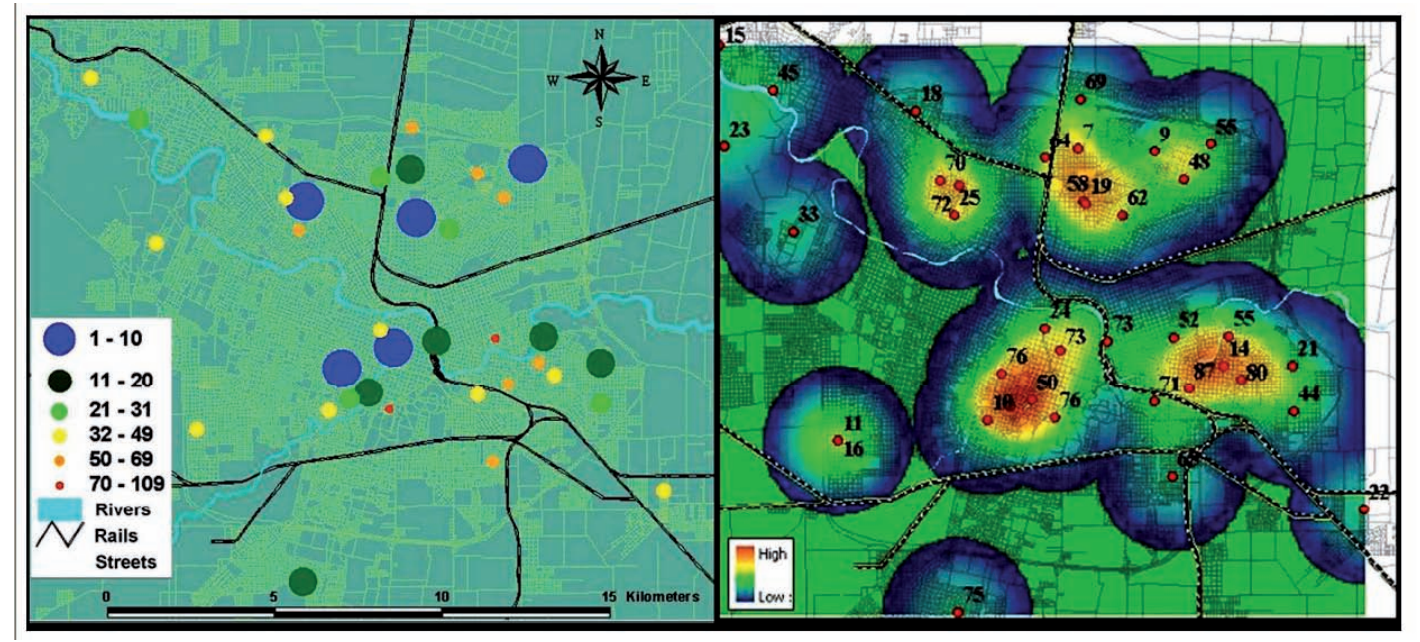

Fig. 3. The left side shows the dynamic diffusion pattern of SLE-registered cases during the 2005 outbreak in Córdoba City (time expressed in days, i.e. the bigger the circles, the earlier the appearance of cases). The right side is a thematic map depicting high- and low-density clusters of confirmed SLE human cases in Córdoba City (January to May 2005) and their relationship with patient age. 
day 50 to the end of the epidemic. We found an inverse linear relationship between the number of SLE cases and distance to high-vigor vegetation as estimated through the NDVI, i.e. $\mathrm{R}^{2}=0.58-(\mathrm{y}=0.194 \mathrm{x}+3.84)$. The median distance between patient location and this vegetation class was $191 \mathrm{~m}$ (6.7 pixels) with a minimum of $0 \mathrm{~m}$, a maximum of $598 \mathrm{~m}$ (21 pixels) and a standard deviation of $123 \mathrm{~m}$ (4.3 pixels). More than $67.5 \%$ of all cases were recorded as living closer than $250 \mathrm{~m}$ to high vigor vegetation and $95 \%$ of them no further away than $325 \mathrm{~m}$. Finally, when taking into account all the patients locations and surrounding

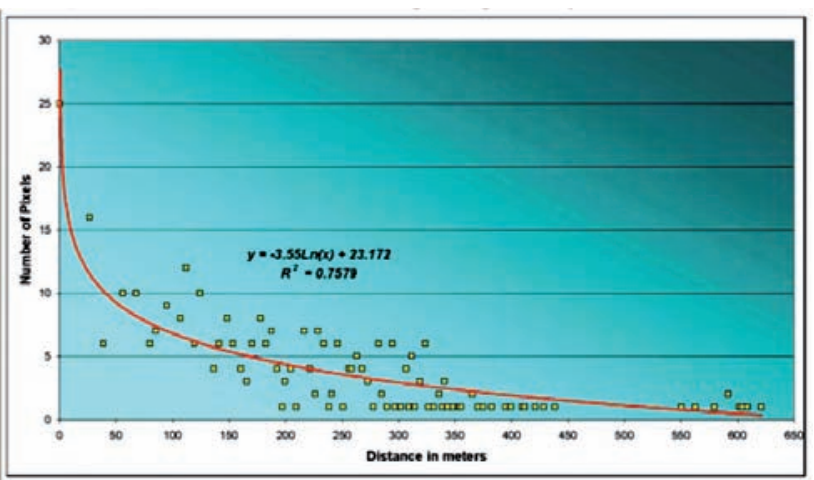

Fig. 4. Relationship between distance to the vegetation class and region of interest (ROI) pixels from influence area of SLE cases.
$(3 \times 3)$ pixels, the logarithmic regression $(y=-3.55$ $\operatorname{Ln}(x)+23.17$ ) showed $R^{2}=0.76$ (Fig. 4). On the other hand, no relationship was found between the number of cases and the other buffer images generated, i.e. neither lentic, nor lotic or mixed water sources.

\section{The decision tree model}

Band1/band4, band7/band4, tasseled cap 2 and the buffer image to high-vigor vegetation sources were selected as predictive variables for developing the SLE tree risk model. Decision criteria nodes for the construction of the decision tree model are showed in Fig. 5.

The assignment of risk levels was performed in a non-hierarchical manner. Levels that fulfilled four node criteria were classified as high-risk, three nodes medium- to high-risk, two nodes medium-risk, while one node alone signified low-risk. Those that did not fulfill or survive any node criterion were considered not to be at risk. As shown in the SLE environmental risk map (Fig. 6), 8.5\% of the whole $882 \mathrm{~km}^{2}$ image subset was classified as high-risk areas and $38 \%$ as norisk areas. This high percentage of no-risk areas was related to the great percentage of croplands, woodlands and unoccupied areas in the subset.

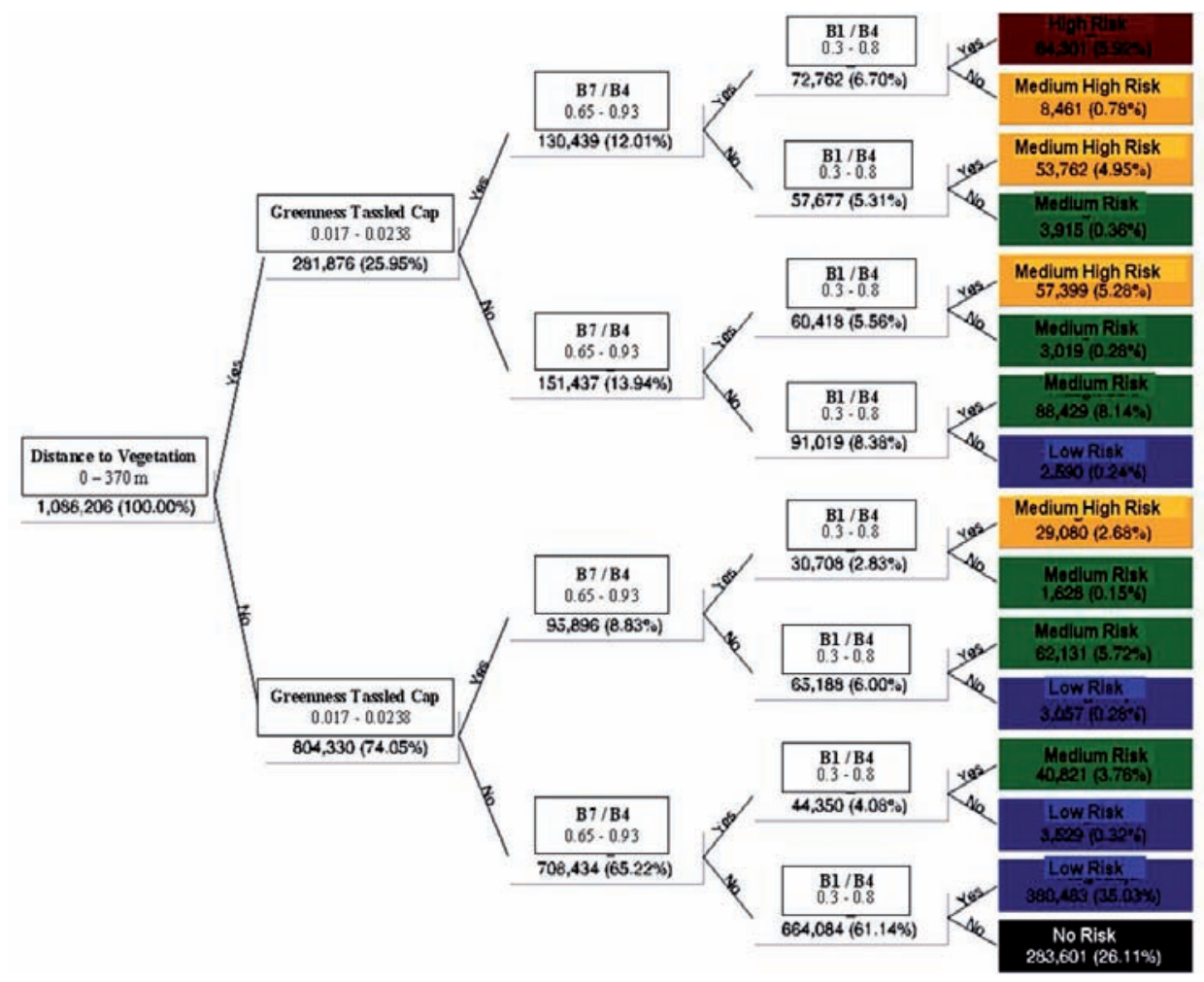

Fig. 5. SLE risk Decision Tree Model showing decision nodes variables and data range, including the percentage of pixels that "survived" each decision and each risk class map percentage (DTM terminal nodes or leaves) referring to Córdoba city and surrounding areas $(30.4 \times 29 \mathrm{~km})$. 

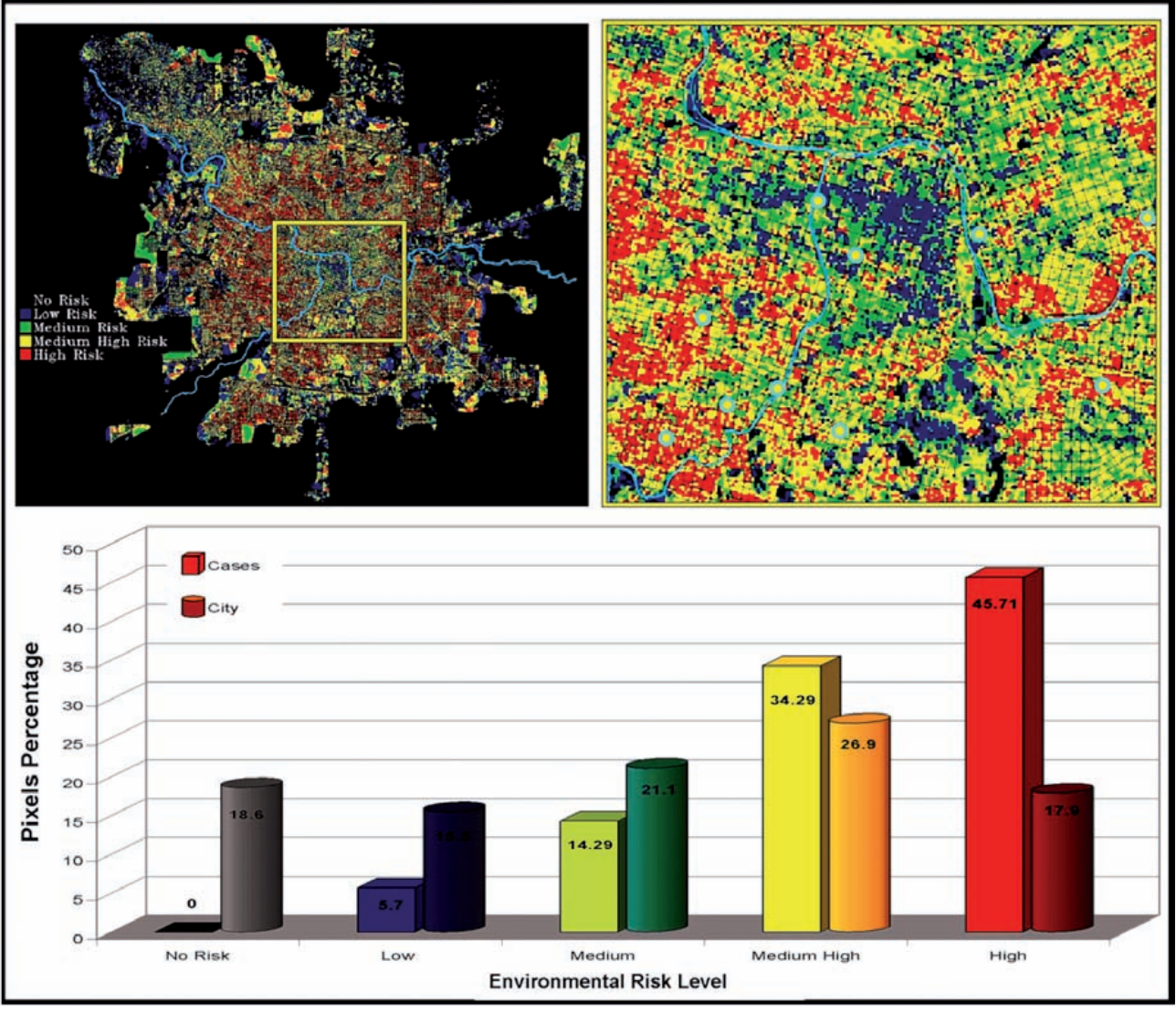

Fig. 6. Top: map of environmental vulnerability to SLE in Córdoba City (different colours represent different SLE risk levels for the 2005 outbreak) with a "zoom in" showing light blue circle areas, wherefrom cases of the SLE 2005 outbreak were reported. Bottom: number and distribution of the pixels in each risk map class, for the whole city (cylinders) and for the patient regions of interest (cubes).

To obtain the real percentage of areas at high environmental risk for SLE, we performed an analysis of the risk based on urban pixels (including parks, squares, unoccupied places, etc.), eliminating crops and surrounding agricultural systems through masking. The SLE environmental vulnerability map showed that $17.9 \%$ of the whole city could be considered as at high-risk for SLE with $34.1 \%$ at no- or low-risk. Of all registered cases, $46 \%$ were from areas considered high-risk and $80 \%$ from areas classified as high-risk or high- to medium-risk (Fig. 6).

\section{Discussion}

In spite of the complexity of the SLE outbreak analysis, GIS depicted the distribution patterns of symptomatic cases well, including the spatial relationships among cases and variables of the macro-habitat derived from remote sensing. The decision to use the patient homes for positioning was based on the greater SLE incidence in patients over 60 (Spinsanti et al., 2008), who usually remained at home at night and thus had more contact with surrounding areas. This decision was also based on the temporal feeding activities (at dusk or night) of potential SLEV vectors and that SLEV infection of poultry (domestic birds) was associated with notified human SLE cases in 2005 (Diaz et al., 2006b). In addition, in lieu of anything better we choose the residential address as the best way to avoid miss-location of places where infection took place.

With respect to the space-time outbreak analysis, the dispersion patterns observed differed significantly from previous studies on dengue epidemics in South America, where dispersion patterns were in the order of hundreds of meters in response to mosquito range of flight (Tran et al., 2004; Rotela et al., 2007). Although the mechanism of introduction and spread of SLE cases throughout Córdoba City remains speculative, there are probable explanations for the vast distribution patterns of distances found, e.g. delayed symptoms not picked up by the surveillance system, great numbers of asymptomatic SLE and underreporting (Tsai et al., 1987; Spinsanti, 2009). Other reasons include citizen movements during transmission hours and unknown contact with hotspot neighbourhoods.

The potential role of birds in the SLEV cycle of viral transport and dispersal is a mechanism that needs to be explored as it could well explain urban dispersion 
patterns at distances greater than 2,000 and 4,000 m. For example, studies of Townsend Peterson et al. (2003) have pointed out the critical role of birds in long-distance transport and dispersal of West Nile virus in the Western hemisphere. Following up on this theme, we consider that movements of infected birds around the City could be the main origin of this longdistance SLEV dispersion pattern. Recent studies in Córdoba city lend credence to this theory by confirming SLEV antibodies in an increasing number of native birds (Diaz et al., 2006b). Another supporting fact is the ongoing destruction of wild-bird habitats in Córdoba province, provoked by native massive forest contraction, resulting in the loss about $76 \%$ to $94 \%$ of original lowland and mountain subtropical dry forests and woodlands between 1969 to 1999 (Zak et al., 2003). Obviously, without representative human serologic samples from the entire city, it is difficult to establish the true patterns. However, we consider that we would understand the system better after renewed mosquito and human studies in Córdoba City coupled with serological studies of birds during capturerelease-recapture activities as this would reveal the role of each member in the SLEV epidemiological web.

Macro-level factors related to the SLEV transmission presented in this paper, such as vegetation proximity, are linked to potential SLEV vector habitats or resting areas as pointed by Cook et al. (2006), but a more precise analysis of each factor would be necessary to achieve a full understanding of these relationships. Similar relationships were found by Brownstein (2002) and Ruiz et al. (2004) for West Nile virus in New York and Chicago, where patterns of human cases were positively associated with vegetation abundance.

Regarding potential mosquito breeding places (water bodies) derived from the satellite images, a major limitation is associated with Landsat TM image spatial resolution (pixel size) and the lack of GIS layers that shows drains and sewers. We therefore suspect that we are unable to fully estimate the habitats of Cx. quinquefasciatus involved in the SLEV transmission cycle based only on this kind of satellite-derived data. These mosquitoes are peridomestic, and suitable breeding habitats are often associated with the disposal of sewage and industrial waste (Monath, 1980), which is generally hard to detected by this type of sensor images.

As pointed by Hay et al. (2000), the usefulness of the type of predictive maps we are concerned with should be confirmed with the study of medium-scale and micro-scales parameters, including prevention feasibilities for the next epidemic wave. Taking into account the SLE notified symptomatic cases of the 2005 outbreak and high SLEV prevalence in humans $(13.3 \%, 16.5 \%$ and $31.0 \%)$ found in three different public health centers by Spinsanti (2009), we assume that a very low percentage of people infected by SLEV were registered due to clinical symptoms. This fact demonstrates the high rate of transmission of the virus in the region and the importance of performing studies to determine the transmission hotspots through serologic surveys.

We consider that the adoption of active arbovirus surveillance systems is an efficient tool for prevention and mitigation of SLE outbreaks as it would help decision-makers and stakeholders to optimise health system responses and focus on prevention. The decision tree has proved a practical tool for highlighting and weighting susceptible areas of SLEV transmission. Our approach has been shown to facilitate the understanding of vector habitat preferences that can promote outbreaks in certain areas, especially those where environmental field data are not available.

The results presented here support the use of remote sensing and GIS in a multidisciplinary prediction and surveillance of epidemics as well as in establishing strategies for SLE control. The goal, feasible only when a precise geo-referencing system is available, is however limited, mainly by the quality of SLE notification and missing enzootic surveillance of mosquitoes and birds.

\section{Acknowledgements}

We thank the Comisión Nacional de Actividades Espaciales (Argentina) for its technological and professional support. This work was supported by the Comisión Nacional de Actividades Espaciales (CONAE) and grants from FONCYT 01-12572, Consejo Nacional de Investigaciones Científicas y Técnicas (CONICET), SECYT-UNC.

\section{References}

Albert DP, Gesler WM, Levergood B, 2000. Classification: Information Generation. In: Albert DP, Gesler WM and Levergood B (Eds). Spatial analysis, GIS and remote-sensing applications in the health sciences. Ann Arbor Press, Chelsea, UK, pp. 163.

Almirón WR, Brewer MM, 1995. Preferencia de hospedadores de Culicidae (Diptera) recolectados en el centro de la Argentina. Rev Saúde Pública 29, 108-114.

Arc Map 9.0. Arcview. Copyright 1999-2004. ESRI inc., CA, USA.

Barnes CM, Cibula WG, 1979. Some implications of remote 
sensing technology in insect control programs including mosquitoes. Mosq News 39, 271-282.

Beck LR, Lobitz BM, Wood BL, 2000. Remote sensing and human health: new sensors and new opportunities. Emerg Infect Dis 6, 217-227.

Berge TO, 1975. International catalogue of arboviruses including certain other viruses of vertebrates. U.S. Department of Health, Education, and Welfare, No. (CDC) 75-8301, 668669.

Breiman L, Freidman J, Olshend R, Stone C., 1984. Classification and regression trees. Monterey, Wadsworth, CA, USA.

Brownstein JS, Rosen H, Purdy D, Miller JR, Merlino M, Mostashari F, Fish D, 2002. Spatial analysis of West Nile virus: rapid risk assessment of an introduced vector-borne zoonosis. Vector Borne Zoonotic Dis 2, 157-164.

Calisher CH, Poland JD, 1980. Laboratory Diagnosis. In: Monath TP (Ed). St. Louis encephalitis. American Public Health Association, Washington, DC, USA, pp. 571-601.

Calisher CH. 1994. Medically important arboviruses of the United States and Canada. Clin Microbiol Rev 7, 89-116.

Chander G, Markham BL, Barsi JA, 2007. Revised Landsat 5 Thematic Mapper Radiometric Calibration. IEEE Geoscience and Remote Sensing Letters 4, 490-494.

Crist EP, Cicone RC, 1984. Application of the tasseled cap concept to simulated thematic mapper data. Photog Eng Remote Sens 50, 343-352.

Cooke WH III, Grala K, Wallis RC, 2006. Avian GIS models signal human risk for West Nile virus in Mississippi. Int J Health Geog 5, 36.

Díaz LA, Almiron WR, Ludueña Almeida F, Spinsanti LI, 2003. Vigilancia del virus Encefalitis de San Luis y mosquitos (Diptera: Culicidae) en la Provincia de Córdoba, Argentina. Entomol Vect 10, 551-566.

Díaz LA, Ré V, Almirón WR, Farías A, et al., 2006a. Genotype III Saint Louis encephalitis virus outbreak, Argentina, 2005. Emerg Infect Dis 12, 1752-1754.

Díaz LA, Konigheim BS, Aguilar JJ, Spinsanti LI, et al., 2006b. Actividad del virus encefalitis San Luis (Flavivirus) en aves durante una epidemia de encefalitis en Córdoba, Argentina, 2005. Acta Bioquim Clin Latinoam 3, 298.

Díaz LA, 2009. Patrones de actividad y estacionalidad del virus St. Louis Encephalitis en Córdoba, Argentina (2009). Tesis de Doctorado en Ciencias Biológicas - Universidad Nacional de Córdoba, Argentina.

Dister SW, Fish D, Bros S, Frank DH et al., 1997. Landscape characterization of peridomestic risk for Lyme disease using satellite imagery. Am J Trop Med Hyg 57, 687-692.

Eisen RJ, Eisen L, 2008. Spatial modeling of human risk of exposure to vector-borne pathogens based on epidemiological versus arthropod vector data. J Med Entomol 45, 181-192.

ENVI Version 4.1. The Environment for Visualizing Images,
Research Systems, Inc. 2004 http://www.RSInc.com/envi (accessed on August 2004).

Glass GE, Morgan III JM, Johnson DT, Noy PM, Israel E, Schwartz A, 1992. Infectious disease epidemiology and GIS: a case study of Lyme disease. Geo Info Systems 2, 65-69.

Gorla DE, 2002. Variables ambientales registradas por sensores remotos como indicadores de la distribución geográfica de Triatoma infestans (Heteroptera: Reduviidae). Ecol Austral 12, 117-127.

Hay S, 2000. An overview of remote sensing and geodesy for epidemiology and public health applications. Adv Parasitol 47, 1-35.

Hayes RO, Maxwell EL, Mitchell CJ, Woodzick TL. 1985. Detection, identification and classification of mosquito larval habitats using remote sensing scanners in earth-orbiting satellites. Bull World Health Organ 63, 361-374.

Instituto Nacional de Estadística y Censos (INDEC), 2001. Resultados correspondientes al Censo Nacional de Población, Hogares y Viviendas. http://www.indec.gov.ar/indec/ingles.asp (accessed on March 2010).

Jarsún B, Gorgas JA, Zamora E, Bosnero E, Lovera E, Ravelo A, Tassile JL, 2003. Caracterización general de la provincia. In: Gorjas JA, Tassile JL (Eds). Recursos naturales de la Provincia de Córdoba. Los Suelos. Córdoba, Argentina, Agencia Córdoba Ambiente e INTA, pp. 23-60.

Jensen JR, 1986. In: Prentice-Hall (Ed). Introductory Digital Image Processing: a Remote Sensing Perspective. Englewood Cliffs, New Jersey, USA, 379 pp.

Kauth RJ, Lambeck PF, Richardson W, Thomas GS, Pentland AP, 1979. Feature Extraction Applied to Agricultural Crops as Seen by Landsat. Proceedings, LACIE Symposium, NASA, Houston TX, USA, pp. 705-721.

Kitron U, 1998. Landscape ecology and epidemiology of vectorborne diseases: tools for spatial analysis. J Med Entomol 35, 435-445.

Knox EG, 1964. The detection of space-time interactions. Appl Stat 13, 25-29.

Kulldorff M, Hjalmars U, 1999. The Knox method and other tests for space-time interaction. Biometrics 55, 544-552.

Linthicum KJ, Anyamba A, Tucker CJ, Kelley, et al., 1999. Climate and satellite indicators to forecast Rift Valley fever epidemics in Kenya. Science 285, 397-400.

Mack TM, Brown BF, Sudia WD, Todd JC, Maxfield H, Coleman PH, 1967. Investigation of an epidemic of St. Louis encephalitis in Danville, Kentucky, 1964. J Med Entomol 25, 70-76.

Monath TP,1980. Epidemiology. In: Monath TP (Ed). St. Louis Encephalitis. American Public Health Association, Washington, DC, USA, pp. 239-311.

Morrison AC, Getis A, Santiago M, Rigau-Perez JG, Reiter P, 1998. Exploratory space-time analysis of reported dengue cases during an outbreak in Florida, Puerto Rico, 1991-1992. 
Am J Trop Med Hyg 58, 287-298.

Murray J, 2003. Mathematical Biology II. In: Springer-Verlag (Ed). Spatial models and biomedical applications. 3rd Edition. Berlin, Germany.

Porcasi X, Calderón G, Lamfri M, Scavuzzo CM, 2006. Predictive distribution maps of zoonoses reservoir rodents in a Southern America. Mastozoología Neotropical 12, 199-216.

Porcasi X, Catalá SS, Hrellac H, Scavuzzo CM, 2006. Infestation of rural houses by Triatoma infestans (Hemipera: Reduviidae) in the southern area of the Gran Chaco in Argentina. J Med Entomol 30, 1060-1067.

Randolph SE, Rogers DJ, 1997. A generic population model for the Africa tick Rhipicephalus appendiculatus. Parasitology 115, 265-279.

Richards A, 1999. Remote Sensing Digital Image Analysis. Springer-Verlag (Ed), Berlin, Germany, 240 pp.

Richards JA, Jia X, 2006. Remote Sensing Digital Image Analysis. Springer-Verlag (Ed), Berlin, Germany, 210 pp.

Rogers DJ, Randolph SE,1993. Distribution of tse tse and ticks in Africa: past, present and future. Parasitol Today 9, 266-271.

Rogers DJ, Randolph SE, 2003. Studying the global distribution of infectious diseases using GIS and RS. Nat Rev Microbiol 1, 231-237.

Rogers DJ, Randolph SE, Snow RW, Hay SI, 2002. Satellite imagery in the study and forecast of malaria. Nature 415, 710715 .

Rotela C, Fouque F, Lamfri M, Sabatier P, Introini V, Zaidenberg M, Scavuzzo M, 2007. Space-time analysis of the dengue spreading dynamics in the 2004 Tartagal outbreak, northern Argentina. Acta Trop 103, 1-13.

Ruiz MO, Tedesco C, McTighe TJ, Austin C, Kitron U, 2004. Environmental and social determinants of human risk during a West Nile virus outbreak in the greater Chicago area, 2002. Int J Health Geogr 20, 8.

Sabattini MS, Avilés G, Monath TP, 1998. Historical, epidemiological and ecological aspects of arboviruses in Argentina: Flaviviridae, Bunyaviridae and Rhabdoviridae. In: Travassos da Rosa APA, Vasconcelos PFC, Travassos da Rosa JFS (Eds). An overview of arbovirology in Brazil and neighboring countries. Instituto Evandro Chagas Press, Belem, Brazil, pp. 113-134.

Sbarato D, Rotela CH, Poggi JA, Cagliolo MF, Campos M, Ortega JE, Salort MR, Carreras S, Cora A, Enrico L, 2004. Plan integral de forestación urbana: Ciudad de Córdoba, Argentina http://www.bvsde.ops-oms.org/sde/opssde/bvsde. shtml. Centro Panamericano de Ingeniería Sanitaria y Ciencias del Ambiente. Organización Mundial de la Salud, 173.

Silverman BW, 1986. Density Estimation for Statistics and Data Analysis. In: Chapman and Hall (Eds). New York, USA.

Spinsanti L, 2009. Epidemiología del virus encefalitis Saint Louis en la provincia de Córdoba. Tesis en Ciencias de la Salud - Universidad Nacional de Córdoba. Facultad de Ciencias Médicas.
Spinsanti L, Basquiera AL, Bulacio S, Somale V, Kim SCH, Ré V, Rabat D, Zárate A, Zlocowski JC, Quiroga Mayor C, Contigiani M, Palacio S, 2003. St. Louis encephalitis in Argentina: the first case reported in the last seventeen years. Emerg Infect Dis 9, 271-273.

Spinsanti L, Díaz LA, Glatstein N, Arselán S, Morales MA, Farías AA, Fabbri C, Aguilar JJ, Ré V, Frías M, Almirón WR, Hunsperger E, Siirin M, Da Rosa AT, Tesh RB, Enría D, Contigiani M., 2008. Human outbreak of St. Louis encephalitis detected in Argentina, 2005. J Clin Virol 42, 27-33.

Spinsanti L, Farías A, Aguilar J, Díaz MP, Ghisiglieri S, Bustos MA, Vilches N, González B, Contigiani M., 2007. Risk factors associated with St. Louis encephalitis seroprevalence in two populations from Córdoba, Argentina. Trans R Soc Trop Med Hyg 101, 1248-1252.

Spinsanti L, Ré V, Basualdo MA, et al., 2000. Seroprevalencia de infección por el virus Encefalitis San Luis en la provincial de Formosa. Medicina (B Aires) 60, 474-476.

Spinsanti L, Ré V, Diaz MP, Contigiani MS, 2002. Age-related seroprevalence study for St. Louis encephalitis in a population from Córdoba, Argentina. Rev Inst Med Trop Sao Paulo 44, 59-62.

Townsend Peterson A, Vieglais DA, Andreasen JK, 2003. Migratory birds modeled as critical transport agents for West Nile Virus in North America. Vector-Borne Zoonotic Dis 3, 27-37.

Tran A, Deparis X, Dussart P, Morvan J, Rabarison P, Remy F, Polidori L, Gardon J, 2004. Dengue spatial and temporal patterns, French Guiana, 2001. Emerg Infect Dis 10, 615-621.

Tsai TF, Cobb WB, Bolin RA Gilman NJ, Smith GC, Bailey RE, Poland JD, Doran JJ, Emerson JK, Lampert KJ, 1987. Epidemiologic aspects of a St. Louis encephalitis outbreak in Mesa County, Colorado. Am J Epidemiol 126, 460-473.

Tsai TF, Smith GC, Happ CM, Kirk LJ, Jakob WL, Bolin RA, Francy DB, Lampert KJ, 1989. Surveillance of St. Louis encephalitis virus vectors in Grand Junction, Colorado, in 1987. J Am Mosq Control Assoc 5, 161-165.

Venables WN, Ripley BD, 1994. Modern Applied Statistics with S-plus. Springer-Verlag, New York, USA.

Wood BL, Beck LR, Washino RK, Hibbard K, Salute JS, 1992. Estimating high mosquito-producing rice fields using spectral and spatial data. Int J Remote Sens 13, 2813-2826.

Xu M, Watanachaturaporn P, Varshney PK, Arora MK, 2005. Decision tree regression for soft classification of remote sensing data. Remote Sens Environ 97, 322-336.

Yang GJ, Vounatsou P, Tanner M, Zhou XN, Utzinger J, 2006. Remote sensing for predicting potential habitats of Oncomelania hupensis in Hongze, Baima and Gaoyou lakes in Jiangsu province, China. Geospat Health 1, 85-92.

Zak MR, Cabido M, Hodgson JG, 2003. Do subtropical seasonal forests in the Gran Chaco, Argentina, have a future? Biol Cons 120, 589-598. 